\title{
Para-além da histeria... 0 gozo feminino
}

\author{
Jessica Dias Belchior, Danielle Belo Lamarca, \\ Carolina Santos Cavalcante e Catarine Souza
}

\begin{abstract}
Resumo
O objetivo do presente trabalho é distinguir e demarcar os encontros e desencontros entre a histeria, gozo fálico, e a feminilidade, Outro gozo. Sobretudo, elucidar a singularidade de cada forma de gozar. Comumente, confunde-se a estrutura histérica com o gozo feminino; entretanto, a histeria não anula a feminilidade. Pelo contrário, encontramos fenômenos clínicos que demonstram esses entrecruzamentos dos dois gozos. Por isso, os fenômenos do feminino na histeria serão diferentes dos da neurose obsessiva. Além disso, há os que pressupõem que só existem mulheres histéricas, mas sabemos que também há os homens histéricos. Diante disso, já sabemos que existem pontos congruentes entre elas, pois $\mathbb{A}$ Mulher comunica-se tanto com o gozo fálico quanto com o Outro gozo. Esta pesquisa teórica busca, por meio dos fenômenos clínicos, percorrer a interseção entre esses dois gozos. Por conseguinte, mostra-se também que, na psicanálise, a histeria é diferente do senso comum, que a entende como uma alteração de emoções, descontrole e gritaria.
\end{abstract}

\section{Palavras-chave:}

Histeria; Feminilidade; Gozo fálico; Gozo feminino.

\section{Beyond hysteria... Female enjoyment}

\begin{abstract}
The objective of this work is to distinguish and demarcate the encounters and mismatches between hysteria, phallic jouissance, and hemininity, Another joy. Above all, it intends to elucidate the uniqueness of each form of enjoyment. Commonly, the hysterical structure is mixed with female enjoyment; however, hysteria does not nullify femininity. On the contrary, we find clinical phenomena that demonstrate this intersection of both joys. Hence, the phenomena of the feminine in hysteria will be different from those of obsessional neurosis. In addition, there are those who assume that there are only hysterical women, but we know
\end{abstract}


that there are also hysterical men. In view of this, we already know that there are congruent points between them, because $\mathbb{A}$ Woman communicates both with the phallic jouissance and the Other joy. This theoretical research seeks, through clinical phenomena, to traverse the intersection between these two joys. Therefore, it is also shown that hysteria in psychoanalysis is different from common sense, which understands hysteria as a change of emotions, out of control and shouting.

\section{Keywords:}

Hysteria; Femininity; Phallic jouissance; Female jouissance.

\section{Además de la histeria... El goce feminino}

\section{Resumen}

El objetivo del presente trabajo es distinguir y demarcar los encuentros y desencuentros entre la histeria, el goce fálico y la feminidad, Otro goce. Sobre todo, dilucidar la singularidad de cada forma de gozar. Es común que se confunda la estructura histérica con el goce femenino. Sin embargo, la histeria no anula la feminidad, pues. Encontramos fenómenos clínicos que demuestran este entrecruzamiento de los dos goces. Por eso, los fenómenos de lo femenino en la histeria serán diferentes de los de la neurosis obsesiva. Además, están los que presuponen que sólo existen mujeres histéricas, pero sabemos que también están los hombres histéricos. Ante esto, ya sabemos que existen puntos congruentes entre ellas, pues LA Mujer se comunica tanto con el goce fálico, como con el Otro goce. Esta investigación teórica busca, a través de los fenómenos clínicos, recorrer la intersección entre esos dos goces. Por consiguiente, se muestra también que la histeria en el psicoanálisis es diferente del sentido común, que entiende la histeria como una alteración de emociones, descontrol y gritería.

\section{Palabras clave:}

Histeria; Feminidad; Goce fálico; Goce femenino.

\section{Au-delà de l'hystérie... La jouissance féminine}

\section{Résumé}

Ce travail a pour but de distinguer et de démarquer les rencontres et les désaccords entre l'hystérie, la jouissance phallique et la féminité, une Autre jouissance, et surtout d'élucider la singularité de chaque façon de jouir. Généralement, la structure hystérique est confondue avec le plaisir féminin, cependant, l'hystérie n'annule pas la féminité. Au contraire, nous trouvons des phénomènes cliniques qui démontrent cette 
intersection de deux joies. Par conséquent, les phénomènes du féminin dans l'hystérie seront différents de ceux de la névrose obsessionnelle. En outre, certains pensent qu'il n'y a que des femmes hystériques, mais on sait qu'il y a aussi des hommes hystériques. Face à cela, on sait déjà qu'il existe des points de convergence entre eux, car A La femme communique tant avec la jouissance phallique qu'avec l'autre jouissance. Ce travail théorique cherche alors, à travers des phénomènes cliniques, à parcourir l'intersection entre ces deux jouissances. Par conséquent, on démontre également que l'hystérie dans la psychanalyse est différente de la perspective du sens commun, qui comprend l'hystérie comme une altération des émotions, déséquilibre et hurlement.

\section{Mots-clés :}

Hystérie ; Féminité ; Jouissance phallique ; Jouissance féminine.

Na base da estrutura histérica, existe um questionamento: "sou homem ou sou mulher?”. Isso pode levar-nos ao engano de correspondê-la ao gozo feminino. Entretanto, a histeria não exclui a feminilidade, pois $\mathbb{A}$ Mulher comunica-se tanto com o gozo fálico quanto com o Outro gozo. O gozo fálico fala sobre o engendramento fantasístico do sujeito neurótico, enquanto o Outro gozo aponta para o infinito, isto é, para a impossibilidade de dizer. Por isso, Lacan (1972-1973/1985) afirma que, entre as possibilidades dessa criação, a mulher precisa criar-se uma a uma pela via da mascarada feminina. Diante desse embate sobre o impossível de dizer o que é ser uma mulher, A Mulher busca, nessa solução, ser o falo que ela não tem.

Para distinguir a singularidade do que é histeria e o que é feminilidade, é importante considerar que existem pontos congruentes entre elas, uma vez que tanto uma quanto outra denunciam o enigma feminino. De acordo com Freud (1908/2015), a relação da triangulação na histeria significa que a histérica escolhe A mulher para que, por intermédio dela, possa desvendar: o que tem essa mulher que faz causar o homem? E, ainda, pelo olhar desse homem, a histérica tenta desvendar o que tem naquela mulher que o atrai.

Em outras palavras, o gozo na histeria não é remetido à satisfação com o objeto em si, como Freud outrora pensara. Para Quinet (2005), o gozo histérico revela sua relação com os objetos, ou seja, nenhum objeto lhe serve, nada basta, nada é suficiente e tão grandioso. Por isso, é possível dizer que, para a histérica, o gozo falhou na reivindicação da consistência de um objeto que venha para salvá-la da inconsistência, o que faz com que a histérica mantenha-se no meio do caminho. Por sua vez, apesar de se prevenir de sua insatisfação, encontra-se sempre fixa em uma castração.

Muitas vezes, histeria e feminilidade são entendidas como uma coisa só, porém Lacan (1972-1973/1985) diz que existe uma separação entre elas. Isto é, há uma diferença entre ser o falo e a posição da mulher. Na histeria, ocorre a identificação 
com o desejo, que impossibilita a identificação com o objeto de gozo. Dessa forma, para que consigamos compreender a histeria e o feminino, devemos, em primeiro lugar, compreender que a histeria corresponde a uma estrutura, e o feminino, a uma posição. Assim, é necessário fazermos uma pergunta que alicerceia a base tanto da histeria quanto do feminino: o que quer uma mulher? Podemos dizer, então, baseando-nos pela fórmula quântica da sexuação proposta por Lacan no Seminário 20 (Lacan, 1972-1973/1985), que ser mulher é uma forma, uma saída para se haver com a falta, o desejo, o gozo e a lei.

Podemos confundir feminilidade com histeria, pois, com frequência, encontramos mais mulheres histéricas do que obsessivas em nossa clínica. Porém, é importante ressaltar que a feminilidade está para além da estrutura. Isto é, tanto mulheres obsessivas quanto mulheres histéricas serão não-todas no gozo fálico, característica peculiar do feminino, e não da estrutura que está referida ao gozo fálico. Portanto, vimos que nem tudo em uma mulher está referido ao falo e ao significante, sendo esta a principal denúncia da histérica: sua insatisfação com os semblantes.

Na histeria, o sujeito, oferecendo-se como objeto $a$ na missão impossível de causar desejo, recria o Outro, cuja castração ele vela, nos dois sentidos - oculta e toma conta. Mas o Outro, para a histérica, não é o homem de cuja castração ela sabe. Para além do homem está o Outro absoluto: mulher, na qual a histérica adora o mistério de sua própria feminilidade e interroga o enigma do gozo para além do falo (Ribeiro, 2011).

A mulher, por sua falta fálica, estaria mais próxima do real, como nos mostram vários casos de mulheres que se queixam de uma falta insuportável. Podemos entender essa falta não apenas como inveja do pênis, mas como a impossibilidade de um semblante que poderia tamponar a falta. Já a histeria pode ser entendida como um protesto contra o menos Um não castrado, que denota a exceção, construindo a regra do todo fálico, negando a mulher, em uma tentativa de se manter no todo fálico.

Lacan (1972-1973/1985), ao trazer o discurso histérico, destacou o fato de que a histeria deseja obter do mestre a produção de um saber. O gozo da privação histérica demanda do Outro que ele revele o álgama da Mulher, ou seja, essa insatisfação esbarra no impossível de dizer e alimenta uma incitação-ao-saber.

Já sabemos que o sujeito humano, da linguagem e do desejo, não é definido pela anatomia, pois sobre o sexo o sujeito nada sabe. Dessa forma, nem o feminino, nem a histeria são uma questão de gênero, uma vez que a posição feminina refere-se ao gozo suplementar que Freud (1931/2010a) apresenta como "um problema a mais". Lacan (1972-1973/1985) traz em sua releitura o conceito de não-toda, referida à lógica fálica. Isto é, não podemos afirmar que somente as mulheres, anatomicamente falando, estejam do lado esquerdo da fórmula, justamente por se tratar de uma posição da qual o sujeito relaciona-se com seu desejo e com o Outro.

O gozo feminino encontra-se dos dois lados: o fálico, que é o gozo sexual propriamente dito, e o não-todo fálico, no qual se situa o gozo Outro. Esse gozo Ou- 
tro é aquele que se relaciona com a falta no Outro e que Lacan considera enigmático. Ele está fora do significante, está para além do falo, exatamente onde se situa o lado feminino. Ademais, Quinet (2012) afirma que essa escolha entre as posições, masculino e feminino, é uma escolha forçada, sem garantias.

O homem goza do objeto $a$ de sua fantasia, recortado no corpo da mulher; trata-se de um gozo que caiu do Outro. Já a mulher é desdobrada em seu gozo: por um lado, relaciona-se com o gozo fálico, caso em que um homem pode ser igualmente sintoma para ela; por outro, relaciona-se com o significante da falta no Outro, isto é, entretém uma relação particular da qual se deduz o gozo Outro, o gozo feminino, fora do falo, pelo qual não se estabelece nenhum tipo de laço com o outro. (Miranda, 2017, p. 100)

Segundo Quinet (2012), o Outro gozo é aquele que se encontra no lado feminino na partilha dos sexos, o não-todo. Esse gozo tem uma lógica diferente da forma fálica, que se encontra no lado masculino no quadro da sexuação. Lacan (1972-1973/1985), ao formular a partilha dos sexos, priorizou a função fálica, e não o fato de possuir ou não possuir o falo em si, dividindo assim: gozo masculino é o gozo fálico, e gozo feminino é o gozo Outro. Lacan, no quadro da sexuação, utilizou as fórmulas quânticas para falar sobre a relação do homem e da mulher com o gozo. $\mathrm{O}$ lado feminino desse quadro não tem uma exceção em relação à mulher, já que Lacan diz que A mulher não existe como universal feminino. Porém, isso não significa que ela não esteja na função fálica e, sim, que está inscrita na função fálica, mas não por inteiro. Vê-se, portanto, que o não-todo fálico é o que define a posição feminina.

Figura 1. Quadro da sexuação de Lacan.

\begin{tabular}{|c|c|c|c|}
\hline & $\overline{\Phi \mathrm{x}}$ & $\overline{\mathrm{g} x}$ & $\overline{\Phi^{x}}$ \\
\hline & $\Phi \mathrm{x}$ & $\overline{\nabla x}$ & $\Phi \mathrm{x}$ \\
\hline \multicolumn{2}{|c|}{8} & $(\mathbb{A})$ & \\
\hline \multicolumn{4}{|c|}{$\Phi \hookrightarrow$} \\
\hline
\end{tabular}

Fonte: Lacan, 1972-1973/1985, p. 105.

De acordo com Soler (2005), o sujeito histérico atravessado pelo feminino diz que, em seu lado da neurose, ou seja, no lado regido pela norma fálica, a histérica deixa insatisfeito o gozo do Outro, querendo um mais-ser. Já do lado mulher, do lado não-toda, a referência ao gozo aparece como um mais. De um lado, um querer gozar e, do outro, um querer ser. Freud (1905/2016) aponta que, na histe- 
ria, existe a triangulação com homem e mulher. Como no caso de Dora (Freud, 1905/2016), por exemplo, a triangulação se dá pela identificação com a mulher, no caso com a Sra. K., no qual a histérica vai tentar descobrir o que essa mulher tem que faz ela ser A mulher para $\mathrm{O}$ homem. E na identificação com o homem, Sr. K., Dora tenta descobrir, pelo olhar desse homem, como ele é causado por essa mulher. Uma vez que o Sr. K. diz não sentir mais nada por sua esposa, cria um significado para Dora, no qual ela perde a referência da pergunta "o que é ser mulher?". Pergunta essa que consistia na base da histeria de Dora, que pretendia descobrir a resposta por meio da triangulação entre o casal.

Soler (2005) elucida que a feminilidade implica a relação com o Outro, que precisa de um homem para se realizar como sintoma. Já a histérica, que também passa pela mediação do Outro, não tem como finalidade o homem para se realizar como seu sintoma, mas é um sujeito emparelhado pelo significante mestre, do qual recorrerá a pergunta quanto a seu desejo. O desejo da histérica, então, sustenta-se no sintoma do Outro.

Lacan (1972-1973/1985) ilustra, no quadro da sexuação, as duas setas que partem da posição feminina em direção ao falo e ao $S(\mathbb{A})$ (gozo feminino). Faz isso com o objetivo de clarificar a comunicação entre o lado homem e o lado mulher que ocorre $\mathrm{n} \mathbb{A}$ Mulher histérica. Segundo Lacan, a escolha de pertencimento a um dos lados na partilha dos sexos é uma escolha de modalidade de gozo: as mulheres histéricas também podem inscrever-se do lado masculino.

Para exemplificar o que foi dito, seguimos com Miranda (2017), que relata a história de Madame Grignan e suas cartas endereçadas à mãe. É possível perceber o quanto a mãe goza falicamente do corpo da filha. Após o casamento desta, diante de uma possível separação, esse gozo desdobra-se para um gozo Outro, sem barras. É o que nos revela em suas cartas, em que sua filha é elevada ao sagrado. Nesse ponto, refere-se a um gozo feminino além do fálico, situando-se fora dele. A autora (Miranda, 2017) também afirma que:

No caso da filha acrescenta-se a dificuldade de não haver um significante que diga A Mulher, o que a deixa sempre em falso: ou a menina banca o homem, fazendo a mascarada histérica, ou cai no vazio da falta do significante que diga A Mulher que não existe, alternativa que precisará saber inventar a mascarada feminina. (Miranda, 2017, p. 104)

A mãe, com o auxílio do meio-dizer, tenta transmitir à filha como construir essa mascarada feminina; esse gozo Outro está fora do significante, está para além do falo. Segundo Lacan (1957-1958/1999), a posição da mulher do lado feminino é de quem já perdeu tudo e não tem mais nada a perder. É retomada a questão do feminino e de sua relação com o falo na afirmativa da dialética fálica, que representa a presença e a ausência, o ter e o ser. Isso tem grande importância no campo da sexua- 
lidade feminina, em que Lacan retoma o conceito da mascarada feminina. Na leitura freudiana (Freud, 1933/2010b), o feminino é visto como um continente negro, o que traz uma possível separação entre ser mãe e ser mulher. Nesse momento, de construção teórica, Freud visualizava uma possível divisão entre a mulher e a mãe.

Dessa forma, de acordo com Freud (1933/2010b), um filho pode até mesmo ter função de objeto fálico e propiciar uma satisfação para a mãe. Entretanto, esse filho não é suficientemente capaz de responder por completo ao desejo da mãe. Lacan (1958) afirma que o filho é o objeto fálico que, ao ser tomado como tal, pode ser passível de satisfazer parcialmente o desejo da mãe. E, de acordo com Soler (2005), existe uma espécie dedutível do desejo feminino em específico, do qual a mascarada proíbe todo acesso direto, e é por tanto velar esse desejo que a mascarada impede que o sujeito o acesse diretamente.

\section{Referências bibliográficas}

Freud, S. (2010a). Sobre a sexualidade feminina. In S. Freud. Obras completas (Vol. 18, 1a ed., pp. 371-398). (P. C. de Souza, trad.). São Paulo: Companhia das Letras. (Trabalho original publicado em 1931)

Freud, S. (2010b). A feminilidade. In S. Freud. Obras completas (Vol. 18, 1a ed., pp. 263-293). (P. C. de Souza, trad.). São Paulo: Companhia das Letras. (Trabalho original publicado em 1933)

Freud, S. (2015). As fantasias histéricas e sua relação com a bissexualidade. In S. Freud. Obras completas (Vol. 8, 1a ed., pp. 339-349). (P. C. de Souza, trad.). São Paulo: Companhia das Letras. (Trabalho original publicado em 1908)

Freud, S. (2016). Três ensaios sobre a teoria da sexualidade. In S. Freud. Obras completas (Vol. 6, 1a ed., pp. 15-108). (P. C. de Souza, trad.). São Paulo: Companhia das Letras. (Trabalho original publicado em 1905)

Lacan, J. (1985). O seminário, livro 20: mais, ainda (M. M. Dias, trad.). Rio de Janeiro: Jorge Zahar. (Trabalho original publicado em 1972-1973)

Lacan, J. (1999). Seminário 5: as formações do inconsciente (V. Ribeiro, trad.). Rio de Janeiro: Jorge Zahar. (Trabalho original publicado em 1957-1958)

Miranda, E. (2017). Desarrazoadas. Rio de Janeiro: Contra Capa.

Quinet, A. (2005). A lição de Charcot. Rio de Janeiro: Jorge Zahar.

Quinet, A. (2012). Os outros em Lacan. Rio de Janeiro: Jorge Zahar.

Ribeiro, M. A. (2011). Um certo tipo de mulher. Rio de Janeiro: 7Letras.

Soler, C. (2005). O que Lacan dizia das mulheres. Rio de Janeiro: Jorge Zahar.

Recebido: 31/03/2019

Aprovado: 20/05/2019 